\title{
HISTOLOGICAL AND IMMUNOHISTOCHEMICAL STUDY OF CHROMIUM TOXICITY IN RAT SUBMANDIBULAR SALIVARY GLANDS
}

\author{
Koura A.S.* and Saad N.M.*
}

\begin{abstract}
24 male albino rats (200-220 mg body weight) were utilized in the current study. They were divided into three groups. The first group was control group (6 rats) received drinking tap water containing permissible correlation of hexavalent chromium $\mathrm{Cr}$ (VI) $50-100 \mathrm{Mg} / \mathrm{L}$ for 4 months. The drinking tap water with added $450 \mathrm{mg} / \mathrm{L}$ of hexavalent chromium as chromium trioxide $\left(\mathrm{Cr}_{2} \mathrm{O}_{3}\right)$ for 4 months. Study group (II) (9 rats) received same drinking water as study group (I) with administrated $2.5 \mathrm{mg}$ vitamin E oil daily along four months. Samples from submandibular salivary glands were prepared for histological examination with (H\&E stains) and immunohistological investigation of ki-67 proliferation matrix. Group (I) animals revealed histopathological degenerative changes in submandibular salivary gland acini. The blood vessels were dilated and engorged. The connective tissue stroma revealed increase in thickness. The immunoexpression of Ki-67 in the nuclei of the cells was less than $5 \%$ of the same group, where the ducts of the acini showed increased percent of Ki-67 expression. Group (II) received vitamin $\mathrm{E}$ in addition to $\mathrm{Cr}$ (IV), showed some recovery to normal structure of the submandibular salivary glands. This might states the protective effect of Vitamin (E) as an antioxidant against cytotoxic effect of hexavalent chromium.
\end{abstract}

\section{INTRODUCTION}

Chromium is a naturally occurring element found in rocks, animals, plants, soil and in volcanic dust and gases. It was stated that chromium is present in the body at birth, a fact that suggests its essential nature. After its absorption chromium disappears rapidly from the blood and is stored in the tissue. ${ }^{(1)}$ It reenters the circulation following the ingestion of glucose. Also, it was found that the plasma concentration of chromium is $0.15 \mathrm{Mg} / \mathrm{ml}$, bound to transferrin ${ }^{(2)}$
Chromium exists in several oxidation states ranging from 2- to $6+$. The most prevalent oxidation states are trivalent (3+) and hexavalent (6+). ${ }^{(3)}$

There is a growing interest in toxicological studies on chromium compounds because of their potential use in modern industries and the consequences of human exposure to these compounds. ${ }^{(4)}$

Chromium is used in three basic industries: metallurgical, chemical and refractory (heat-

*Associate Professor of Oral Biology Department, Faculty of Dentistry, Alexandria University

**Lecturer of Oral Biology Department, Faculty of Dentistry, Alexandria University 
resistant applications), and these industries are second largest source of ambient chromium. ${ }^{(5)}$

The health effects of chromium are at least partially related to the valence state of the metal at the time of exposure of the two environmentally available terms of chromium, hexavalent and trivalent; the hexavalent form has been demonstrated to be associated with the toxic parameters and classified as human carcinogen and mutogen. ${ }^{(6)}$

In the body, chromium (6) is reduced by several mechanisms to chromium (3) already in the blood before it enters the cells. The chromium (3) is excreted from the body, whereas the chromate ion is transferred into the cell by transport mechanism but during the process of reduction, reactive oxygen intermediates that have the ability to react with DNA are then formed. This interaction with DNA is believed to mediate the genotoxic effects of hexavalent chromium. ${ }^{(7)}$

The tetrahedral hexavalent ion has been shown to enter the cell through general union channels and bind to cellular components, causing disruptions in biochemical pathways. ${ }^{(6)}$

The most common toxic effects of hexavalent chromium are dermatitis, allergic reactions, skin and mucos membrane ulcerations, gastroenteritis and hepatocellular deficiency. ${ }^{(9)}$ After oral or dermal absorption of $\mathrm{Cr}$ (IV), kidney is the main target organ for chromium accumulation, which may result in acute tubular necrosis in humans. ${ }^{(14)}$ It was demonstrated that acute oral toxicity of chromium (VI) range between 50 and $150 \mu \mathrm{g} / \mathrm{L} \cdot{ }^{(15)}$ Chromium genotoxicity is manifested as gene mutations, several types of DNA lesions and inhabitation of addition chromium cytotoxicity may lead to cell cycle arrest, apoptosis or neoplastic transformation. ${ }^{(9)}$

Antigen Ki-67 is a protein that in humans is encoded by the MKI67 gene (antigen identified by monoclonal antibody Ki-67). Antigen KI 67 is a nuclear protein that is associated with cellular proliferation. ${ }^{(10)}$ It is furthermore associated with ribosomal RNA transcription. ${ }^{(11)}$ Inactivation of antigen KI-67 leads to ribosomal RNA synthesis. ${ }^{(12)}$

The expression of human Ki-67 protein is strictly associated with cell proliferation. During interphase, the antigen can be exclusively detected with the nucleus, whereas in mitosis most of the protein is relocated to the surface of the chromosomes. Ki-67 protein is present during all active phases of the cell cycle $\mathrm{G}(1), \mathrm{S}, \mathrm{G}(2)$, and mitosis but is absent from resting cells $G(0)$, makes it an excellent marker for determining the so-called growth fraction of a given cell population. However, Ki-67 protein expression is an absolute requirement for progression through the cell division cycle. ${ }^{(10-13)}$

Ki-67 could be identified replicating cells of benign and malignant lesions. ${ }^{(16)}$ Higher expression of this marker has been shown in aggressive tumors. ${ }^{(17)}$

The submandibular salivary glands are one of the most widely studied of the salivary glands due to its characteristic and histological features. They are sensitive to changes in the body where they response to a number of systemic and local factors.

Vitamin $\mathrm{E}$ is an essential nutritional element. It has a biological antioxidant activity for a variety of metabolites, hormones, enzymes and nutrients. It was demonstrated that it maintain the function of intracellular organelles and cellular membrane integrity. ${ }^{(18)}$

No available studies according to our knowledge were done to investigate the effect of vitamin $\mathrm{E}$ as an antioxidant on the submandibular salivary glands of male albino rats and the immune enhancer response after toxicity of hexavalent chromium $\mathrm{Cr}$ (VI) .

\section{MATERIAL AND METHODS}

Twenty four, male albino rats of weight ranging between $(200-240 \mathrm{gm})$ were used in this study. The animals were kept in the animal house at the medical technology center for research and services, Medical Research Institute, Alexandria University. 
The animals were kept under the same environmental conditions from the beginning of the experiment in plastic cages. The animals were classified into 3 groups:

Control group: consisted of six rats which received tap water containing permissible concentration of hexavalent chromium $\mathrm{Cr}$ (VI) 50$100 \mathrm{ug} / \mathrm{L}$ "according to Washington Environmental protection agency, 200" for the period of 4 months."

Study group: This was subdivided into:

Group I: consisted of 9 rats all placed in one large cage. The rats received drinking tap water with added $450 \mathrm{Mg} / \mathrm{L}$ of hexavalent chromium $\mathrm{Cr}$ (VI) as chromium trioxide $\left(\mathrm{Cr}_{2} \mathrm{O}_{3}\right)$ supplied in the form of brownish red granules* for 4 months.

Group II: consisted of 9 rats all placed in one large cage received the same drinking water as in group (I). In addition, the animals were given oral doses of vitamin $\mathrm{E}$ in oil (2.5 mg) daily along the four months.

The drinking water containing hexavalent chromium was prepared by weighting the toxic, and the measured amount were added and dissolved in 1 liter of tap water.

\section{Obtaining of specimens and tissue preparation}

Samples of submandibular salivary glands were obtained after 4 months of the experimental period. Rats of all groups were sacrificed by cervical decapitation then submandibular salivary glands were carefully dissected at and fixed in 10\% neutral buffered formation for histological and immunohistochemical examination.

The right submandibular salivary glands were prepared to be examined by light microscope while the left submandibular salivary glands were prepared for immunohistochemical examination.

\section{Histological examination}

Specimens from submandibular salivary glands were washed and divided into two halves, one half was prepared for light microscopic examination using Hematoxylin and Eosin (H\&E) stain. The other half was prepared for immunohistochemical examination for detection of Ki-67 proliferation marker. ${ }^{(19,20)}$

\section{RESULTS}

Histological examination of control group sections of submandibular salivary glands revealed; the glandular tissue was formed mainly of series acini with few numbers of mucous acini among them, in addition to normal duct system.

A well encapsulated gland surrounded by a moderately thick connective tissue capsule from which connective septa divided the gland into lobe and lobules.

The serous acini appeared round with a narrow lumen. The acini were lined by pyramidal cells with apical acidophilic cytoplasm, their nuclei were prominent, deeply stained, and spherical in shape and basally situated. Duct system included the intercalated, secretory striated, granular convoluted tubules and excretory ducts showed normal appearance.

Thick fibrous connective tissue was present between the lobes and lobules of the submandibular salivary glands. (Fig 1)

Both acini \& ducts revealed negative immune reaction to Ki-67. (Fig 2)

Submandibular salivary glands examinations of study group (1) revealed that the daily administration of $\mathrm{Cr}$ (VI) at higher doses caused multiple histopathological \& immunohistochemical changes.

\footnotetext{
* Win lab laboratory chemical reagents. Leicestershore, LE6. 9E, UK.
} 


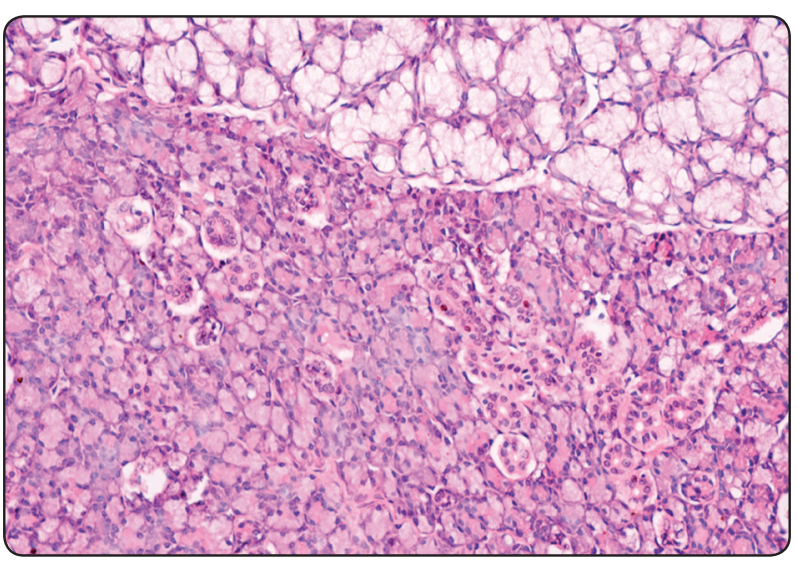

Fig. (1) Photomicrograph of submandibular salivary gland of the control group showing groups of predominantly serous acini, some mucous acini, intercalated ducts. Well formed fibrous connective tissue is present inbetween the lobules. (H\&E X200).

Hydropic degeneration of the cytoplasm with illdistinct cell boundaries and vacuolization in the acini could be detected. The duct systems were dilated and their cytoplasm showed complete signs of degeneration. (Fig 3)

The serious acini appeared distorted with cytoplasmic vaculation. The nuclei of the acinar cells showed large prominent hyperchromatic appearance with obliterated lumen. (Fig 4).

The connective tissue stroma, both intra and interlobuler revealed increase in collagen fiber condensation and inflammatory cell infiltration (Fig 5). All blood vessels were congested, dilated and with irregular endothelial wall. (Fig 6)

The nuclei of the acinar cells of the study group (II) showed intense immunoreactivity for Ki-67. The cytoplasm of the acinar cells revealed weak positive immune reaction. The nucleic of the epithelium lining the ducts revealed intense immunoexperssion to Ki-67. (Fig 7)

Examination of the submandibular salivary glands of study group II showed recovery to normal structure. The acini were arranged in normal fashion. Where some acinar cells revealed

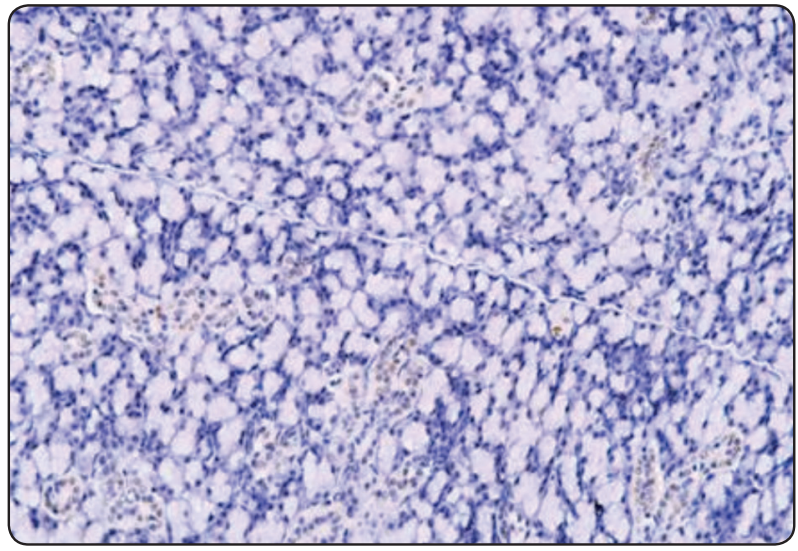

Fig. (2) Photomicrograph of submandibular salivary glands of albino rats of control group showing negative immune reaction (ki-67x200).

typical appearance with eosinophilic zymogen granules, however other cells were distended with cytoplasmic signs of degeneration: the ducts were dilated and with normal epithelial lining. (Fig 8,9)

The nuclei of most of the acini showed weak immunoexpantion Ki-67. (Fig 10)

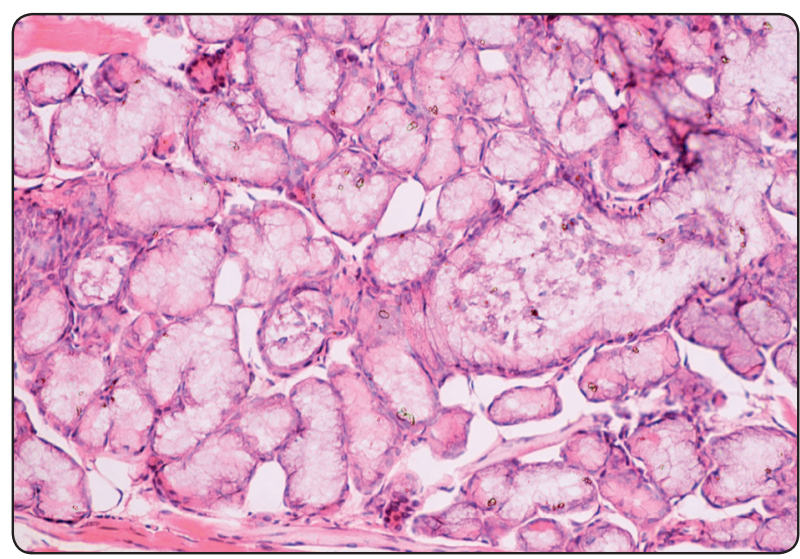

Fig. (3) Photomicrograph of submandibular salivary gland of study group (I) showing degenerative changes in connective tissue septa with thickened basement membrane and vaculation of mucous acini. Note nuclei are compressed towards basement membrane. (H\&E $\mathrm{X} 400)$. 


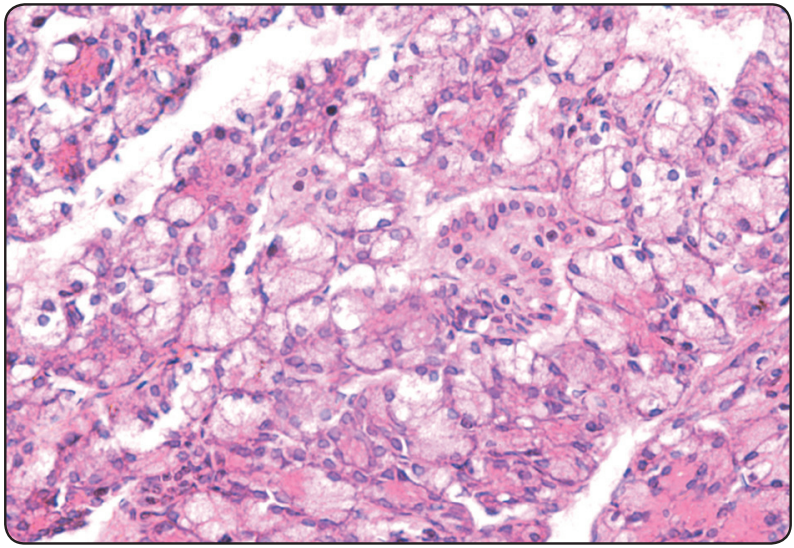

Fig. (4) Photomicrograph of submandibular salivary glands of study group (I) showing distorted serous acini with prominent hyperchromatic nuclei and obliterated lumen. The cytoplasm showing vaculation with areas of fused secretion. (H\&E X200).

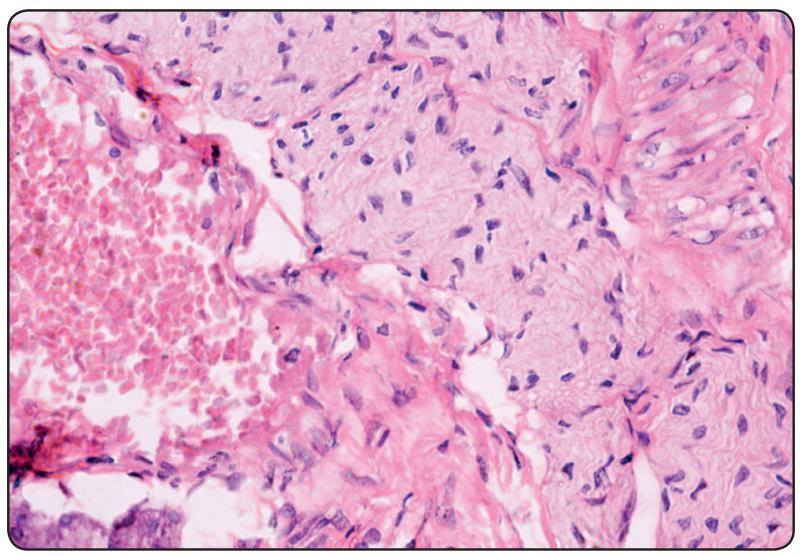

Fig. (6) Photomicrograph of submandibular salivary glands of group (I) showing dilation of blood vessels with irregular endothelial wall (H\&E X400).

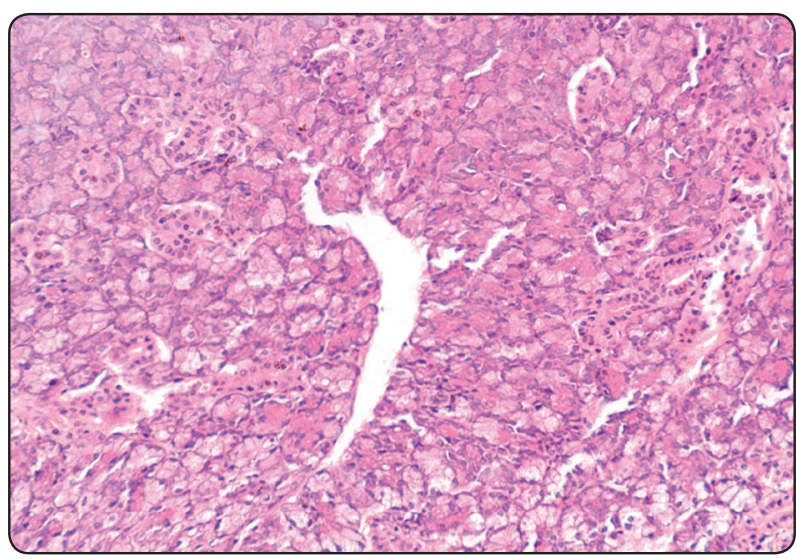

Fig. (8) Photomicrograph of submandibular salivary glands of group (II) showing serous salivary tissue with nearly normal appearance (H\&E x200).

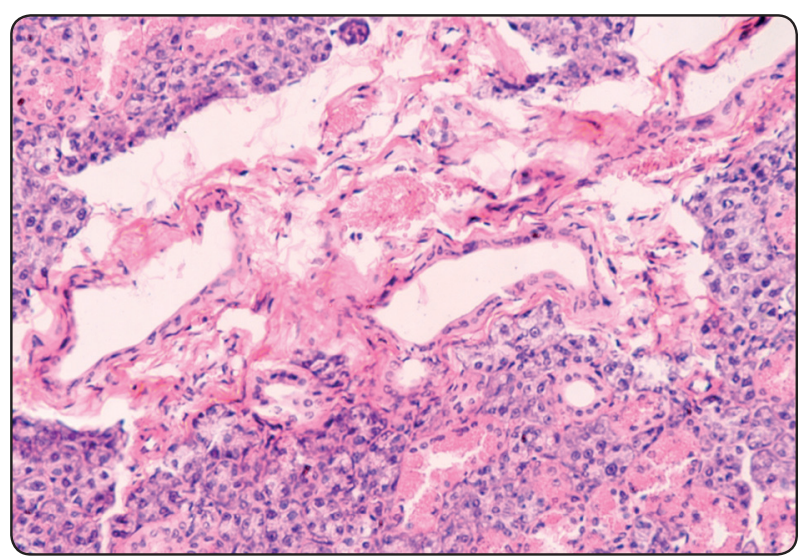

Fig. (5) Photomicrograph of submandibular salivary glands of group (I) showing wide connective tissue stroma with inflammatory cells infiltration.(H\&E X 200)

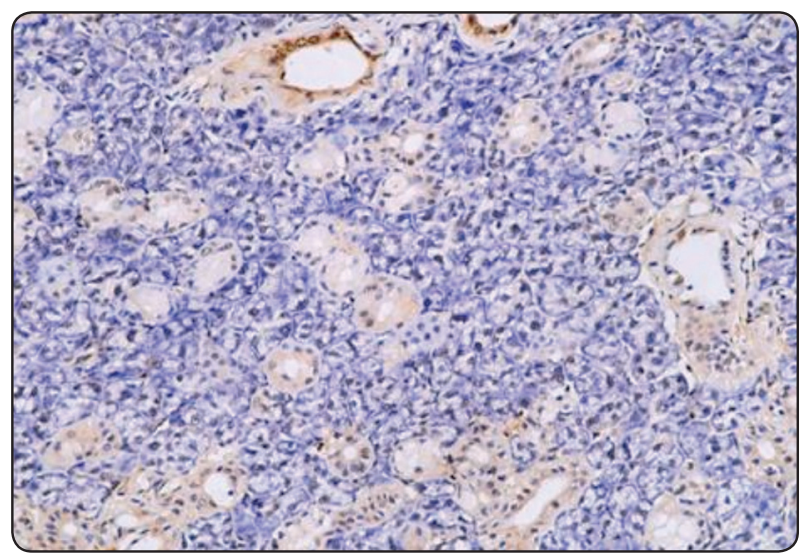

Fig. (7) Photomicrograph of submandibular salivary glands of albino rats group (I) showing immuno-expression response of the nuclei with very low proliferation index less than $5 \%$ (Ki- $67 \times 200)$.

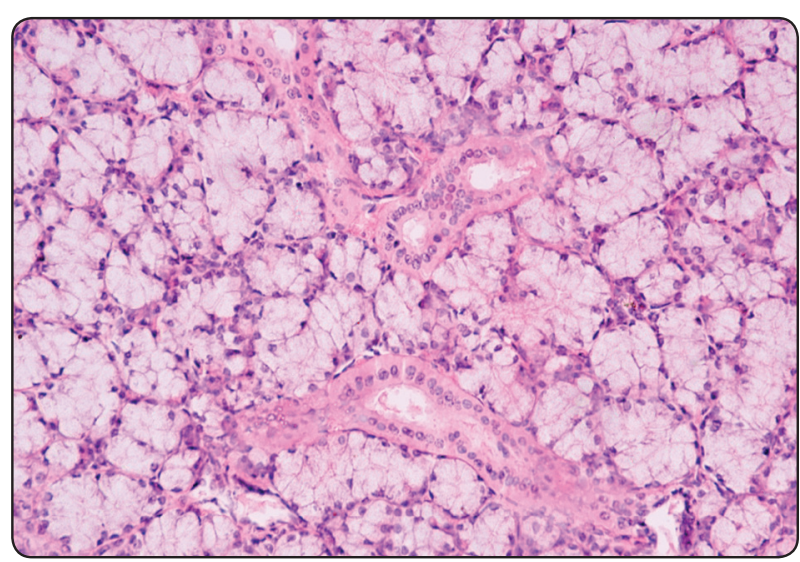

Fig. (9) Photomicrograph of submandibular salivary glands of group (II) showing normal appearance of mucosa salivary tissue (H\&E X200). 


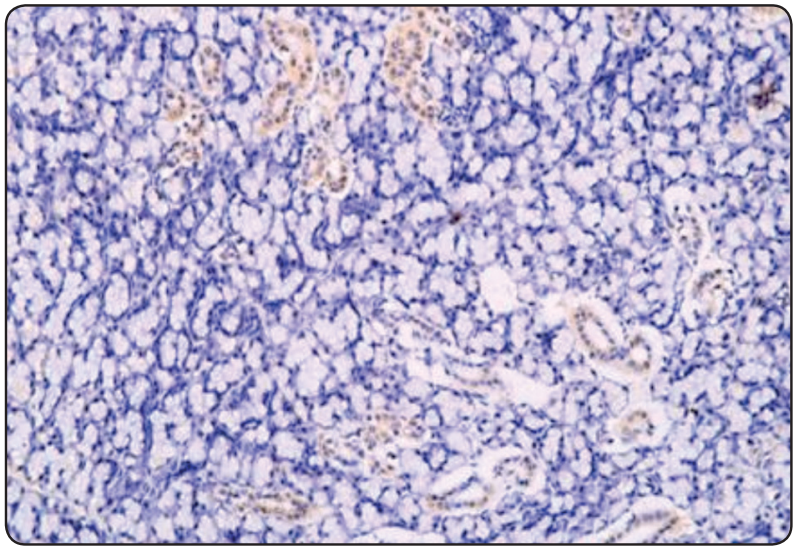

Fig. (10) Photomicrograph of submandibular salivary glands of group (II) showing negative expression of $\mathrm{Ki}-67$ in the nucleic of acinar cells (Ki-67x200).

\section{DISCUSSION}

The greatly increased circulation of metals through the soil, water and air, and their inevitable transfer to the human food chain remains an important environmental issue that entails some unknown health risks for future generations.

Chromium has become a subject of much interest in recent years; many studies have been carried out on the effect of chromium toxicity on various organs. Hexavalent chromium is through to be the most toxic of the released metal ions. It has been classified as an environmental and occupational human carcinogen by the International agency for Research on Cancer IARC. ${ }^{(21)}$

Chromium at the physiological levels is involved in the regulation of normal carbohydrate metabolism in mammal and so it is considered as an essential trace element. ${ }^{(22)}$

The entry routes of chromium into the human body are inhalation, ingestion and dermal absorption. Occupational exposure generally occurs through inhalation and dermal contact, whereas the general population is exposed mostly by ingestion through chromium control in soil, food \& water. ${ }^{(23)}$

In the present work, the effect of chromium administration on the submandibular salivary glands of male albino rats was studied. Doses of chromium used in the study were not usually found in the environment but may be encountered in the workplace in the vicinity of industrial establishment as mentioned by Kanojia et al. ${ }^{(24)}$

The dose given to the study group I, II (450 ppm) corresponded to the chromium concentration in ELMex Bay. ${ }^{(25)}$

At the end of the study, the animals of the studied groups became aggressive. These behavioral changes were more observed in groups I than II This could be demonstrated by the fact that the exposure to chromium compounds causes decrease in the weight of the glands resulting in a profound effect on the territorial aggression of the male mice. ${ }^{(26)}$

The results of the present study showed that chromium administration to the rats of the study groups resulted in many histopathological changes in the submandibular salivary gland. Examination of study groups I, II, revealed that the serous acini showed progressively change in size as compared to the control group. This could be explained by the fact that the change of size of the cells permits it to remain viable despite the in appreciate changes in the environment as mentioned by Kaplan. ${ }^{(27)}$

Acharya S. et al stated that the rat liver and kidney treated with chromium showed vaculation, disruption of the arrangement of the hepatocytes and vaculation in the glomeruli; this could explain the disarrayed arrangement and progressive increase in the amount of cytoplasmic vacuolation of the serous acini. (28)

The connective tissue septa showed increased in thickness and hyalinization. The blood vessels were enlarged and congested. Degeneration is one of the evidence of cell injury as suggested by Greshan. ${ }^{(29)}$

Vaculation can be a sign of injury and hence it was suggested that the damage to the villas epithelium resulted in crypt epithelial hyperplasia in mice as stated by Thomson et al (2012). ${ }^{(30)}$ Many potential causes of vacuolization were suggested including altered lipid metabolism, endoplasmic reticulum stress or proteasome dysfunction (Franco cidlouksi 2009). ${ }^{(31)}$ 
Also, it could be attributed to the damage of the cell nuclei by the long term toxic effect of chromium. ${ }^{(32,33)}$ The observed cellular changes in terms of chromium condensation, morphological changes and DNA fragmentation might be due to the cytotoxic effect of chromium at the nuclear level. ${ }^{(34)}$

Bewer LM et al investigated the lung injury, inflammation, proliferation and survival signaling responses after repetitive exposure to particular chromium. It was demonstrated that Injury \& inflammation correlated with airways becoming immunoreactive for phosphorylation of the survival signaling protein $\mathrm{AKI}$ and the proliferation marker Ki-67. ${ }^{(35)}$

Klein-Szanto et al examined the $\mathrm{Ki}-67$ proliferation index of cell proliferation in normal oral epithelia and leukoplakias, their results showed that although the basal layer of normal epithelia showed a very low proliferation activity, oral leukoplakias, even these containing low grade dysplasia, exhibited a very significant increase in proliferation.

High grade dysplasia could be clearly differentiated from low grade dysplasia and normal oral epithelia by the presence of proliferating cells in the superficial cell state. It was stated that $\mathrm{Ki}-67$ seems to be the most reliable immunohistochemical marker for future use in cancer prevention and therapeutic clinical trials. ${ }^{(36)}$

This could demonstrate our findings as the chromium toxicity showed many morphological changes of the cells with a very low increase in proliferative activity in the acini. As the duct systems have a higher proliferative activity than acinar cells they showed increased proliferative activity by Ki-67.

Vitamin $\mathrm{E}$ is an antioxidant that prevents the oxidation activity of chromium. It maintain the biological functions integrity and stability of cell membrane. ${ }^{(37)}$

In this respect it a plays a role in maintain and functions of the intercellular organelles' as lysosomes and mitochondria. ${ }^{(38)}$
This was demonstrated in our work from study groups I and II where effect of chromium toxicity followed by normalization depending on the role of vitamin $\mathrm{E}$ as an essential biological antioxidant. ${ }^{(39)}$

\section{CONCLUSION}

From the current study we can conclude that vitamin $\mathrm{E}$ is an essential nutrient element which could help restoring the integrity of damaged salivary acinar cells after degenerative effect of chromium toxicity.

\section{REFERENCES}

1. Scayer HJ. Chromium and iots compound. In: Zenz L, Dickers OB, Hovate EP (eds). Occupational medicine. $3^{\text {rd }}$ ed. St Louis: Mosby. year book, Inc, 1994. pp. 457-95.

2. Eastwood M. Principles of human nutrition, $1^{\text {st }}$ ed. London, UK: Chapman \& Hall, 1997.

3. Yamini H, Ravikunarb T, Rabub M, Unni NB. Cytotxicity studies \& chromium (III) complexes on human dermal. fibroblasts. Free Radic Biol Med 2005; 38: 58-69.

4. Vasant C, Balmcirrugen $\mathrm{K}$, Rajaram R, Ranasami T. Apoptic of lymphocytes in the presence of $\mathrm{Cr}(\mathrm{V})$ complexes: Role in $\mathrm{Cr}$ (VI) induced toxicity. Biochem Biophys Res common 2001; 285: 1354-60.

5. Norsete $\mathrm{J}$. The carcinogencity of chromium and it salts. $\mathrm{Br}$ J Indt Med 1986; 43: 649-51.

6. International Agency fir Research in Cancer (IARC). Monographs on evaluation of the carcinogenic risks of chemicals to humans: $\mathrm{Cr}, \mathrm{Ni}$ and molding. Lyon: IARC. 1990; 49-256.

7. Hathcock JN. vitamins and minerals: efficacy and safety. Am J Clin Nutr 1997; 66: 427-37.

8. Stearns DM, Kenendy LJ, Coartoey KD, Cianograde PH, Phieffer LS, Wetetrhahn KE. Reduction of chromium(VI) by ascorbate leads to chromium-DNA binding and DNA strand breaks in vitro. Biochemistry 1995; 34: 910-9.

9. Shimada H, Shiao YH, Shibata M, Waullres MP. Cadmium suppresses apoptosis induced by chromium. J Toxicol Environ Health A 1998; 54: 159-68.

10. Schenk DM, Kujpers HJ, Van Drunen E, Van Dalen $\mathrm{CH}$, Ceuts van Kessel AH, Vehejen R, Ramaelcers FC. Assignment of the gene(s) induced in the expression of the proliferation - related Ki-67 antigen to human chromosome. Hum Genet 1989; 83: 297-9. 
11. Bullwinkel J, Baron-Luher B, Ludemann A, Wohlenberg C, Cierdes J, Scholzen T. Ki-67 protein is associated with RNA transcription in quiescent and proliferation cell. $\mathrm{J}$ Cell Physiol 2006; 206: 624-35.

12. Rahmanzadeh R, Huttmann G, Gerdes J, Scholzen T. Chromphore. associated light inactivation of p Ki-67 leads to inhabitation of ribosomal RNA systems. Cell Prolif 2007; 40: 422-30.

13. Scholzen T, Gerdes J. The Ki-67 Prolein: from the known and the unknown. J Cell Physiol 2000; 182: 311-22.

14. Dartsch PC, Hilderbrand S, Kimmel R, Schmahl FW. Investigatian in the nephrotoxicity ad nepatotoxicity of trivalent and hexavalent chromium compound. Int Arch Occup Environ Health 1998; 71: 540-5.

15. Kotas J, Stasides Z. Chromium occurrence in the environment and methods of its speciation. Environ poluut 2000; 101: 263-83.

16. Itall PA, Levision DA, Woods AL, Yule W, Kellock DB, Waticins IA. Profileration cell nuclear antigen (PLNA) immune localization in paraffin sections and index of cell profileration with evidence of deregulated expression on some neoplasm. J Path 1990; 162: 285-94.

17. Lazzaro B, Cleveland D. P53 and Ki 67 antigen expression in small oral biopsy specimens of salivary gland tumors. Oral Surg Med Oral Path Oral Radiol Endod 2000; 89: 613-7.

18. Dinka PJ, langer EH, Vocks SK, Marrow FD. Nutritional Correlates of atrophic glossitis. Possible role of Vit E in papillary atrophy. J Am Coll Nutr 1993; 12: 14-20.

19. Alves FA, Pires FR, De Almeida OP, Lopes MA, Kowalski LP. PCNA, Ki-67 and p53 expressions in submandibular salivary gland tumours. Int J Oral Maxillofac Surg 2004; 33: 593-7.

20. Ramos VaraJA.Technical Aspectof Immunohistochemistry. Vet Pathol 2003; 42: 405-26.

21. Gunaratram M, Grent MH. Chromium (VI) induced damage to the cytoskeleton and cell death in isolated hepatocytes. Biochem Soc Trans 2002; 30: 748-50.

22. Gale TF. The embyotoxic response to maternal chromium trioxide exposure in defect strains of hamsters. Environ Res 1982; 29: 196-203.

23. Hansen MB, Johansen JD, Menne T. Contract chromium allergy; significance of both $\mathrm{Cr}$ (III) and $\mathrm{Cr}$ (VI). Contact Dermatitis 2003; 49: 206-12.

24. Kanojia RR, Janaid M, Marthy RC. Emburyo and fetotoxicity of hexavalent chromium: A long - term study. Toxicol Lett 1998; 95: 165-72.
25. El Dajani SZ. State of pollution of ElMex Ray in chromium compounds. Master degree in Chemistry. Arab Academy of Maritime and Technology, 2002.

26. Elbetieha A, Al Hamood MH. Long term exposure of male and female mice to trivalent and hexvalent chromium compounds. effect on fertility. Toxicology 1997; 116: 39-47.

27. Kaplan SH. Pathology. $1^{\text {st }}$ ed. shKaplan educational center LTD, 1987. pp. 3-8.

28. Acharya S, Mehta K, Krishnan S, Vaman Rao C. a subtoxic interactive toxicity study of ethanol and chromium in male Wistar rats. Alcholol 2001; 23: 99-108.

29. Greshan GA. A coloured atlas of general pathology. $1^{\text {st }}$ ed. Wolfe Medical Publication LTD, 1971. pp. 59-62.

30. Thompson CM, Proctor DM, Haws LC, Herbert CD, Crimes SD, Shatzer HC, et al. Investigation of the made of action underlying the tumorigenic response induced in $\mathrm{B} 6 \mathrm{C} 3 \mathrm{FI}$ mice exposed orally to hexvalent chromium. Toxicol Sci 2011; 123: 58-70.

31. Franco E, Cidlowski JA. Apoptosia and glutathiane Beyond an antioxidant. Cell Death Differ 2009; 16: 1303-14.

32. Liu K, Husler J, Ye J, Leonard SS, Cutler D, Chen F, et al. on the mechanism of CR (VI) induced carcinogen; dose dependence of uptake and cellular response. Mole Cell Biochem 2001; 222: 221-9.

33. Kanojia RK, Junaid M, Murthy RC. EMbyi and fetotoxicity of hexavalent chromium. Along term study. Toxicol left 1998; 95: 165-72.

34. Maygoats KR, Yazzie M, Steams DM. Ultrastructural chance in chromium picolinate treated cells: a TEM study. J Bid Inorg Chem 2002; 7: 791-8.

35. Beaver LM, Stemny EJ, Schwartz AM, Damscer JM, Constant SL, Ceryak SM, et al. Lung inflammation, injury and proliferative response after repetitive particular hexavalent chromium exposure. Environ Health Perspect 2009; 117: 1896-902.

36. Liu SC, Klein-Szanto AJ. Markers of Proliferation in normal and leukoplakic oral epithelia. Oral Oncol 2000; 36: $145-51$.

37. Stajn A, Ruzkis B, Ognjanovic ZS. effect of cademium and selenium on the antioxidant defense system in rat kidneys. Comp Biochem Physiol 1997; 117: 167-72.

38. Eliades T, Pratsinis H, Kletsas D, Eliades G, Makeu M. Characterization and cytotoxicity of ions released from stainless steel nickel-titanium orthodontic alloys. Am J Orthod dentofacial Orthop 2004; 125: L 24-9.

39. Chapple II. Reactive oxygen species and antioxidants ion inflammatory diseases. J Clin Periodontal 1997; 24: 287-96. 